\title{
A gestão de mão-de-obra e os sistemas de produção no Terceiro Mundo
}

JOHN HUMPHREY

produção enxuta tem sido apresentada como uma mudança na
natureza da manufatura, suplantando a produçáo em massa. Ela
envolve modificaçōes em todos os estágios do processo de colocaçáo de produtos nas mãos dos consumidores: incluindo relaçōes com fornecedores, projeto e engenharia, organizaçáo interna da fábrica e distribuição. Neste trabalho, o enfoque recairá sobre o gerenciamento de fábricas e, em especial, nas implicaçóes de novos métodos de produção para o trabalho e para as relaçóes trabalhistas no Brasil.

A mão-de-obra é crítica para a produção enxuta. Os proponentes dos métodos de produçáo enxuta argumentam que os mesmos iráo transformar a natureza do trabalho e modificar radicalmente as relaçóes trabalhistas. Jones (1990) sumariza a organização da produção enxuta em termos de cinco princípios:

" - o maior número possível de tarefas e responsabilidades é transferido para aquelas que realmente agregam valor ao produto na linha;

- a existência de um sistema efetivo para detectar imediatamente defeitos e problemas e rastreá-los até sua origem, com o intuito de assegurar que os mesmos não se repitam. A produção em pequenos lotes - o Just-in-Time, e o objetivo de Zero Defeito ... constituem uma disciplina essencial dentro da fábrica para descobrir problemas...;

- a existência de um sistema de informaçáo compreensivo de modo que todos possam responder rapidamente a quaisquer problemas e entender a situação geral da fábrica;

- nada disto é possível a menos que a força de trabalho esteja organizada em grupos de trabalho, os quais necessitam ser treinados para executar todos os serviços em sua área - incluindo reparos em máquinas, verificaçáo da qualidade, solicitaçáo e arrumaçăo de material - e para resolver seus próprios problemas; 
- este alto nível de envolvimento com a soluçảo proativa de problemas não pode funcionar sem um forte senso recíproco de obrigaçáo entre a firma e seus funcionários" (Jones, 1990:5)".

Os três primeiros princípios enfatizados por Jones alterariam o trabalho executado pelos trabalhadores de produção. Eles executariam tarefas feitas anteriormente por outros funcionários, e teriam que trabalhar com um nível mais elevado de qualidade, confiabilidade e continuidade. As tarefas dos funcionários de manutenção e controle da qualidade seriam alteradas ou eliminadas. Isto significaria, tambem, que os trabalhadores teriam de estar preparados para mudar o que fazem rapidamente, em resposta a problemas e eventos não previstos. $O$ quarto e o quinto princípios são corolários dos três primeiros princípios no tocante às relaçóes sociais - entre os trabalhadores e entre o trabalhador e a gerência. Trabalho em grupo, envolvimento e obrigaçóes recíprocas são os fatores que tornam a produção enxuta possível.

Estes princtpios chave da produção enxuta, conforme resumido por Jones, podem ter outras implicaçóes. O trabalho em grupo e de tarefas múltiplas implica maior treinamento. Obrigaçóes recíprocas envolvem certa estabilidade na relação emprego, pelo menos para a força de trabalho mais importante. As demarcaçóes de funçáo desaparecem e as hierarquias funcionais são comprimidas. Estas modificaçóes possuem implicaçōes importantes para os sistemas de relaçóes industriais e para os sindicatos.

O projeto IMVP sustentou que o impacto da produçáo enxuta sobre o trabalho seria fortemente positivo (1). Foi sugerido que as qualificaçóes da mão-de-obra e a qualidade do trabalho seriam ampliadas e que as relaçóes trabalhadores-gerência se tornariam mais cooperativas. De acordo com Womack; Jones; Roos: "A produçáo enxuta é uma maneira superior de os seres humanos fazerem as coisas... Ela proporciona um trabalho mais desafiador e satisfatório para os funcionários em todos os níveis, da produçăo até os escritórios centrais" (1990:225).

Apesar de estabelecer uma ligação tão forte entre a organizaçáo do trabalho, as práticas de emprego e as relaçóes trabalhadores-gerência, nem Jones (1990), nem o projeto IMVP em geral (Womack; Jones; Roos, 1990) fornecem quaisquer dados empíricos para dar suporte às suas alegaçóes. $O$ estudo do IMVP não enfoca diretamente o trabalho. As alegaçóes sobre o trabalho surgem como um resultado lógico das modificaçóes no processo de produção. A natureza das mudanças na produçáo é vista como requerendo modificaçóes nas relaçóes trabalhogerência, $e$ também, simultaneamente, propiciariam a base sobre a qual estas modificaçōes podem ser realizadas. 
Esta insistência na necessidade de mudança e em sua profunda complexidade, mas ao mesmo tempo em sua factibilidade assegurada, é comum na literatura sobre novas formas de organização do trabalho dos estudos sobre os métodos japoneses (Schonberger, 1982, entre muitos outros), até a literatura sobre a Especialização flextipel (Piore \& Sabel, 1984) e Sistemofatura (Hoffman \& Kaplinsky, 1988). Uma transformação radical do trabalho e das relaçóes trabalhistas é vista como necessária, possível e benéfica para o trabalho. Parecem existir três razóes para isto. Primeiramente, as novas formas organizacionais são consideradas como essenciais para a sobrevivência da companhia, e, portanto, devem ser adotadas a todo custo. As companhias têm que encontrar caminhos para fazê-las funcionar. Em segundo lugar, as novas formas organizacionais são vistas como provadoras de um ambiente de trabalho melhor e mais variado. Como Wood tem argumentado, muitos defensores do JIT e de outros métodos japoneses pressupóem que os métodos criam seu próprio clima positivo de relações trabalhistas (Wood, 1992:10). Em terceiro lugar, supóe-se que os novos sistemas de produçáo os quais dependem grandemente na mão-de-obra para produzir com boa qualidade no tempo previsto; sáo vulneráveis a rupturas; e buscam sugestóes dos trabalhadores para efetuar melhorias no processo de produçáo, só podem ser baseados apenas na concordância e participaçáo ativas do trabalhador.

Em contraste com estas alegações, a pesquisa sobre a prática de JIT/TQC nas companhias japonesas no Reino Unido proporcionam evidência de aumento do controle e intensificaçáo do trabalho (2). De acordo com Delbridge; Turnbull; Wilkinson, "Um sistema JIT/TQM realmente implica, conforme seus defensores gostam de enfatizar, uma devolução de responsabilidades tradicionalmente controladas pela administração. Para o nível do líder de grupo ou do operador, entretanto, isto năo conduz à autonomia, mas antes conduz a um conjunto crescente (e crescentemente oneroso) de tarefas que são monitoradas de perto e estritamente controladas ... O sucesso do sistema de manufatura JIT/TQM em termos de intensificação do processo de trabalho é resultado do aumento da fiscalizaçáo e monitoramento das atividades dos trabalhadores, do crescimento da cobrança do endurecimento da pressão exercida por seus pares dentro dos grupos e através dos clientes e do estímulo ao envolvimento com a eliminafáo do desperdício e com a melhoria contínua do processo de produção" (1992:1).

Esse tipo de sistema de produção altamente visível pode ser combinado com políticas trabalhistas as quais negam aos trabalhadores a ação coletiva efetiva, através da marginalizaçáo de sindicatos ou de seu reconhecimento, de tal forma que iniba os protestos; e identificam a 
extensão do envolvimento dos trabalhadores e provêem um sistema claro de recompensas e puniçóes. Nestas circunstâncias, é possível ambos, reduzir a vulnerabilidade destes sistemas às interrup̧̧óes e também assegurar um grau de envolvimento do trabalhador com base tanto no controle e compulsão quanto no consentimento e compromisso. No Japão, em particular, avaliaçóes de pessoal altamente individualizadas, que possuem conseqüências importantes para o salário e a promoçáo, encontram-se no centro dos regimes JIT/TQC (Ogasawara, 1992). No final das contas, os trabalhadores podem ainda preferir trabalhar sob este tipo de regime do que sob o fordismo clássico (presumindo-se que possuam experiência em ambos ou qualquer possibilidade real de escolha), mas perceber as condiçōes de trabalho na produçăo enxuta desta maneira abre a possibilidade de examinar como as condiçóes para JIT/TQC são estabelecidas em situaçóes diferentes, e como o balanço entre consentimento e compulsão, envolvimento e controle, pode variar na prática (3).

Até recentemente, pouca pesquisa havia sido realizada sobre a implantaçáo da produção enxuta nos países do Terceiro Mundo. $O$ projeto IMVP discute o comércio inter e intra-regional e sugere que um país como o Brasil deveria concentrar-se na produçăo para os mercados da América Latina (Posthuma, 1991:6-7). Nenhuma barreira à transferência da produçăo enxuta para o Terceiro Mundo é antevista: "Algumas fábricas no México e na Coréia do Sul também fizeram progressos consideráveis, especialmente onde as mesmas possuem associaçăo próxima com um produtor japonês enxuto - é possível transferir a produção enxuta para qualquer local" (Jones, 1990:4).

Entretanto, a viabilidade de transferência e seu impacto na mãode-obra necessitam de muito mais atenção. Uma série de questóes têm que ser consideradas. Primeiramente, existe qualquer evidência de sistemas JIT/TQC sendo difundidos em países do Tereeiro Mundo? Em segundo lugar, quais os tipos de políticas que facilitam ou impedem a difusáo de métodos de produção enxuta? Em terceiro lugar, se os sistemas JIT/TQC aumentam as qualificaçóes, será a disponibilidade de qualificaçóes uma barreira para a implantaçăo destes métodos fora daquelas economias, tais como Coréia e Taiwan, que investiram pesadamente em educação durante um longo período de tempo (4)? $\mathrm{Em}$ quarto lugar, se os sistemas JIT/TQC necessitam de relaçóes trabalhistas cooperativas, qual impacto terão em países onde as relaçóes trabalhistas têm sido pobres e conflitivas, como no Brasil nos anos 80 e na Coréia desde 1987? As gerências mudaráo suas posturas quanto às relaçóes de trabalho, ou tentarăo adaptar os sistemas JIT/TQC às condiçóes trabalhistas existentes? Em quinto lugar, existirão variantes de sistemas 
JIT/TQC mais adequadas aos processos de produçáo mais simples, que são, freqüentemente, transferidos aos países do Terceiro Mundo (montagem de eletrônicos, por exemplo) e estes possuiriam o mesmo impacto nas qualificaçōes e relaçóes trabalhistas que aquele previsto pelo projeto IMVP para a indústria automotiva?

Estas questốes sáo consideradas neste artigo para o caso do Brasil. Os dados aqui apresentados foram extraídos de um estudo realizado em 18 companhias produtoras de produtos discretos em dois estados industriais, São Paulo e Rio Grande do Sul (5). O estudo concentrou-se $\mathrm{em}$ assuntos relacionados com a qualidade $\mathrm{e}$ a produtividade na indústria de manufatura brasileira, em especial nas implicações para a mão-deobra direta da adoçáo de elementos do Just-in-Time (JIT) e Total Quality Control(TQC).

Tabela 1

Características da Amostra do IPEA

\begin{tabular}{lllll}
\hline \multicolumn{1}{c}{ Lia. } & \multicolumn{1}{c}{ Setor } & Propriedade & Tamanho(a) \\
\hline A & Interior, São Paulo & Peças Automotivas & Brasileira & $>1000$ \\
B & Interior, São Paulo & Peças Automotivas & Multinacional & $>1000$ \\
C & Grande São Paulo & Pç.Automot. & Multinacional & $\mathbf{5 0 0 - 9 9 9}$ \\
D & Grande São Paulo & Pç.Automot. & Brasileira & $500-999$ \\
E & Interior, São Paulo & Máq.Pesadas & Brasileira & $\mathbf{5 0 0 - 9 9 9}$ \\
F & Grande São Paulo & Aços Espec. & Brasileira & $\mathbf{5 0 0 - 9 9 9}$ \\
G & Grande São Paulo & Embal.de Alumínio & Brasileira & $\mathbf{5 0 0 - 9 9 9}$ \\
H & Grande São Paulo & Eletr./Comunic. & Multinacional & $100-249$ \\
J & Interior, São Paulo & Elétrica & Multinacional & $\mathbf{5 0 0 - 9 9 9}$ \\
L & Interior, São Paulo & Calçados & Brasileira & $>1000$ \\
R & Interior, RGS(b) & Roupas Cama/Mesa & Brasileira & $\mathbf{5 0 0 - 9 9 9}$ \\
S & Interior, RGS & Maquin.náo eletr. & Multinacional & $\mathbf{5 0 0 - 9 9 9}$ \\
T & Grande P. Alegre & Roupas Cama/Mesa & Multinacional & $\mathbf{5 0 0 - 9 9 9}$ \\
U & Grande P. Alegre & Veículos & Brasileira & $\mathbf{5 0 0 - 9 9 9}$ \\
W & Interior, RGS & Cutelaria & Brasileira & $\mathbf{2 5 0 - 4 9 9}$ \\
X & Interior, RGS & Mobiliário & Brasileira & $\mathbf{2 5 0 - 4 9 9}$ \\
Y & Interior, RGS & Computadores & Brasileira & $\mathbf{5 0 0 - 9 9 9}$ \\
Z & Interior, RGS & Calçados & Brasileira & $\mathbf{5 0 0 - 9 9 9}$ \\
& & & &
\end{tabular}

Observaçōes:

(a) Apenas trabalhadores manuais

(b) Rio Grande do Sul

Fonte: Fleury \& Humphrey (1992:107). 
No momento da pesquisa, existia interesse considerável no Brasil sobre os métodos de produçáo que são vistos como o motivo do sucesso japonês, apesar de relativamente poucas companhias começarem a adotá-los, e número menor delas adotou sistemas JIT/TQC na íntegra. A pesquisa orientou-se para companhias as quais, pelo que se sabia, estavam tentando fazer progresso nesta área - das firmas pioneiras e já bastante citadas até companhias apenas iniciando o processo. $O$ estudo examinou firmas usando métodos como Statistical Process Control SPC (Controle Estatístico de Processo), controle de produçáo kanban (e outros métodos que integram produção e estoques menores), designação de tarefas de inspeção aos trabalhadores da produção, tarefasmúltiplas e o envolvimento dos trabalhadores na resolução de problemas. O estudo não esperava encontrar todas estas práticas em todas as companhias, nem pressupunha que as mesmas estariam a caminho da adoção de todas elas. Ao invés disso, era assumido que no núcleo dos novos sistemas de produçáo estavam os princípios de fluxo melhorado de produtos e materiais através da fábrica; qualidade na fonte e resolução sistemática de problemas de qualidade; e melhoria contínua de sistemas de produção, que pode envolver a resolução de problemas por muitas pessoas diferentes na empresa. Este enfoque é mais restrito que o da produção enxuta, que abrange a empresa toda. Este estreitamento do foco foi uma escolha deliberada, objetivando tornar o projeto mais administrável e concentrando a atenção nos trabalhadores diretos da produção.

\section{JIT/TQC na produção brasileira}

Existe um interesse considerável no Brasil pelo Japáo e pelos sistemas de produção que derivam da experiência japonesa. Este interesse tem sido reforçado pela Política Industrial e de Comércio Exterior do governo brasileiro, introduzida em 1990, que foi desenhada para melhorar a competitividade da indústria. A política comercial busca aumentar a pressáo competitiva sobre os fabricantes brasileiros através da liberação das importaçōes. Por trás desta estratégia está a percepşão de que a proteção conduziu a uma indústria local ineficiente, e a competição externa é vista pelo governo como a melhor maneira de promover a modernização da indústria. A política comercial é uma parte central da política industrial como um todo, mas o governo acredita também que o aumento na competiçáo tem de ser acompanhado por uma política industrial que tenha como objetivo melhorar a capacidade das companhias de competirem tanto nos mercados externos quanto com os fabricantes estrangeiros no mercado interno. Um aspecto importante desta política é o Programa Brasileiro para Qualidade e Pro- 
dutividade - PBQP, cujo objetivo é melhorar o desempenho da atividade manufatureira gerando e propiciando apoio a iniciativas nas áreas de qualidade e produtividade. Estas compreendem desde melhorias nos Serviços Públicos (melhores serviços de metrologia, implantaçáo das normas ISO 9000 etc.) até campanhas para elevar a conscientização sobre qualidade entre consumidores e produtores.

Algumas dessas iniciativas estáo nas áreas de JIT e TQC. Certamente existe grande interesse entre as companhias brasileiras líderes por inovaçóes nesta área. Uma pesquisa recente realizada entre 132 companhias de ponta mostrou que $44 \%$ declarava que mais que $20 \%$ da força de trabalho em suas fábricas mais avançadas, estava envolvida em TQC e 39\% das companhias declararam ter a mesma proporção de sua força de trabalho envolvida em JIT interno. Até o ano 2000 estas companhias esperam que estes números atinjam $87 \%$ e $81 \%$ respectivamente (Ferraz; Rush; Miles, 1992:132-36) (6).

As evidências disponíveis mostram que os métodos JIT/TQC podem ser implantados pelo menos em algumas firmas. Um estudo detalhado de Lima sobre sete companhias líderes no Rio Grande do Sul mostrou avanços significativos nas áreas de redução de estoques de matérias-primas e de produto em processo (work-in-progress), tamanho das áreas de armazenagem, tempo gasto para um produto se movimentar através da fábrica, distância percorrida pelos produtos, retrabalho e perdas de materiais (Lima, 1989:114-128). Similarmente, a pesquisa do IPEA encontrou algumas companhias que também estão fazendo grandes melhorias nestes pontos. Foi encontrada grande variedade de inovaçóes, inspiradas por uma série de gurus, incluindo Crosby, Deming, Juran e Ishikawa. As firmas introduziram células de produçăo, reorganizaram os layouts, dividiram a produção em minifábricas, desenvolveram relafōos de clientes entre seções diferentes da fábrica, introduziram cartóes kanban em certos pontos do processo de produçáo, introduziram alguma flexibilidade funcional da mão-de-obra, retiraram inspetores e reorganizaram o papel do departamento de controle da qualidade. A lista não está completa, mas indica a extensão das mudanças que estão sendo feitas. Em alguns casos, os resultados foram notáveis. Uma das companhias pesquisadas, a Firma J, havia reduzido o tempo gasto para fabricar um produto de $\mathbf{4 3}$ dias para quatro, cortado o lead time em $86 \%$ e reduzido as perdas de produção em mais de $90 \%$ (7). Esses resultados foram obtidos em quatro anos, e a companhia (uma subsidiária de uma transnacional européia) tinha objetivos claros quanto a melhorias adicionais, avaliando-se não em função da competição local, mas tendo como padráo o desempenho de uma companhia japonesa líder na área. 
O estudo do IPEA encontrou evidências de ganhos reais na produtividade e qualidade resultantes da adoçáo de técnicas associadas com o sucesso da produção japonesa. Nas companhias mais avançadas, uma transformação profunda em andamento era claramente evidente. No caso da Companhia $\mathrm{S}$, por exemplo, a fábrica havia sido replanejada em sete minifábricas, cada uma responsável por suas próprias atividades e desfrutando de um relacionamento de cliente com as outras áreas. $O$ desempenho mensal de cada minifábrica era avaliado com relaçáo a um conjunto de metas. As metas estavam baseadas em cinco indicadores básicos:

- valor adicionado - outputs da minifábrica, menos inputs;

- eficiência global - cálculo da produção real em comparação com a produção potencial total, levando-se em consideração as perdas e o tempo em que as máquinas, em áreas cruciais do departamento, estavam realmente em operaçáo;

- qualidade - baseada em auditorias da qualidade;

- perdas e retrabalho como uma proporção da produção total;

- atendimento das necessidades do mix de produtos - pelo menos $\mathbf{9 5 \%}$ da produção planejada de cada produto deveria ser atingida no mês.

Em alguns casos as metas de desempenho eram constantes, enquanto em outros casos elas aumentavam no decorrer do ano, ou de ano para ano. Em cada minifábrica grandes quadros demonstrativos indicavam as metas mensais para cada indicador $e o$ desempenho mensal real no ano corrente. A cada mês, o desempenho era analisado $e$ a administraçáo superior reunia-se com os trabalhadores e supervisores em cada minifábrica para discutir as razóes do sucesso ou da falha em cada um dos indicadores. Cada minifábrica recebia pontos de acordo com seu desempenho em cada um dos cinco indicadores para cada mês: 100 pontos eram ganhos pelo cumprimento de uma meta; menos para uma falha em atingi-la em quantidades dadas, e até 150 pontos por ultrapassá-la em quantidades dadas. A cada seis meses o desempenho geral de cada minifábrica era calculado. Para $\mathbf{3 0 0 0}$ pontos (uma média de $\mathbf{1 0 0}$ pontos para cada meta para cada um dos seis meses), os trabalhadores no departamento recebiam um bônus de metade de seu salário mensal. Minifábricas que atingissem 3.300 pontos receberiam 65 por cento de bônus, e aquelas que falhassem em atingir os objetivos receberiam menos que 50 por cento.

Delineando indicadores e recompensas de acordo com o desem- 
penho nas áreas de qualidade, utilização de máquinas, flexibilidade de produção (atendimento a demandas do mix de produto), e valor adicionado, a companhia foi capaz de motivar os trabalhadores e concentrar as mentes da administração na companhia. Haviam sido introduzidas células de manufatura, SPC, treinamento intensivo, alguma integraçáo das funçóes de qualidade e de ajuste de máquina nas tarefas da produção, melhoria no fluxo, redução no tempo de setup etc. Tudo isto resultou melhorias nas perdas, nas rejeiçóes no final do processo de produçáo, nos tamanhos dos lotes, na capacidade para atender pedidos imprevistos e na produtividade. Entretanto, a companhia não havia adotado, e não pretendia adotar, o rodízio de trabalhadores entre tarefas ou um sistema pull de produçáo. A produção enxuta pode ser atingida de diferentes maneiras. Os princípios essenciais de fluxo, qualidade na origem e melhoria contínua estavam presentes.

Na Firma $S$, e também em um conjunto de outras companhias, as tentativas sistemáticas para transformar o processo produtivo acarretaram grandes mudanças para a mão-de-obra. Em particular, o treinamento, a adoção de tarefas múltiplas e qualificaçōes múltiplas devem ser mencionados. As firmas que fizeram bastante progresso com programas de qualidade e produtividade também investiram pesadamente em treinamento e no estabelecimento de objetivos claros para o treinamento. Este treinamento náo objetivava unicamente trabalhadores qualificados. Os cursos eram oferecidos a todos os trabalhadores da produção. Um único exemplo pode ilustrar este ponto. A Firma A sustenta ter treinado uma média de 80 horas por trabalhador em 1990, com a meta de 85 horas em 1991. Ela oferece grande variedade de cursos, começando com SPC e círculos de qualidade (8 horas cada) e incluindo JIT ( 8 horas), matemática básica ( 60 horas), mediçáo e controle (30 horas), desenho técnico ( 40 horas) e hidráulica ( 30 horas). Possui seu próprio Centro de Educação para ministrar estes e outros cursos. Reestruturou sua estrutura ocupacional e salarial e está definindo as necessidades de treinamento para suas células de produçáo, que estão, agora, usando SPC. O treinamento é visto pela administraçáo superior como parte essencial do programa para elevar a qualidade e a produtividade.

O principal problema encontrado pelas companhias que estáo adotando treinamentos extensivos é o baixo nível educacional dos trabalhadores da indústria. Entre os 18 gerentes das fábricas entrevistados para o estudo do IPEA, a educação básica foi citada por 14 como uma área crucial, que deveria ser melhorada pela política governamental. Os padrōes educacionais são baixos no Brasil. Nas áreas de alfabetização e educaçáo básica - educação primária e secundária - o Brasil se compara desfavoravelmente não apenas com relação à Ásia Oriental, mas 
também com outros países em industrialização na América Latina (Amsden, 1989:218). Em 1983, 76,2\% dos empregados na indústria na Coréia tinham pelo menos a educaçáo secundária (Amsden, 1989:222). $\mathrm{Na}$ regiāo industrial mais avançada do Brasil, o estado de São Paulo, o número equivalente para 1987 era de 14,3\% (E. Leite, 1990:22). A maioria dos empregados jovens na indústria continua não tendo a educaçăo primária completa (Fleury \& Humphrey, 1992:66). Em resposta a isto, algumas companhias oferecem cursos de alfabetização, matemática e estatística elementar (Gitahy \& Rabelo, 1991:21). Algumas companhias da amostra do IPEA preparavam-se para atividades de controle de qualidade provendo cursos com títulos a exemplo de Como participar de uma discussáo. Além disso, algumas firmas oferecem educação para adultos conduzindo à conclusáo do primeiro grau (8 anos) ou segundo grau ( 11 anos). Estes programas, vistos mais extensivamente nas Firmas $\mathrm{T}$ e V, foram projetados para compensar as deficiências dos seus funcionários quanto a leitura, redação, raciocínio e habilidade de comunicação. Estes pontos são essenciais se se pretende que os trabalhadores se beneficiem com o treinamento.

Em algumas firmas, a introdução de elementos de JIT/TQC foi acompanhada pela reestruturação de ocupações de modo a refletir o trabalho flexível e as novas políticas de treinamento e promoçáo. Roesch \& Antunes (1990) descrevem o início desta mudança na Firma V. Tendo organizado a produçáo em células e minifábricas e unido estas unidades usando JIT, a companhia chegou à conclusáo de que seus trabalhadores não estavam mais operando como operadores de função única - montador, operador de prensa, inspetor etc. - mas estavam assumindo uma série de funçóes. Uma nova estrutura ocupacional foi planejada, envolvendo cinco categorias ocupacionais, cada uma com requisitos claros de educação e treinamento claros. Uma estratégia similar foi encontrada na Firma A.

É difícil saber, pelo exame da estrutura ocupacional apenas, em que extensão os trabalhadores são multifuncionais. Mesmo que uma companhia reduza o número de categorias ocupacionais a apenas três ou cinco, isto não significa que os trabalhadores têm, na prática, o treinamento e a experiência para mover-se entre muitos trabalhos diferentes (8). Em algumas das firmas mais avançadas estudadas na pesquisa, foi sugerido que uma multifuncionalidade generalizada, envolvendo a capacidade de desempenhar uma série de trabalhos diferentes, era indesejável. Na Firma J, por exemplo, foi sugerido que os trabalhadores necessitam desempenhar as suas funçóes com intervalos freqüentes para náo esquecer como fazê-lo ou perder velocidade de operaçăo. Se todos os trabalhadores fossem multifuncionais, então poderia haver rodízio - 
o movimento constante de trabalhadores entre locais diferentes no processo produtivo, $e$ isto conduziria a um declínio na produtividade. Como resultado, a Firma J designou apenas $20 \%$ de seus trabalhadores como multifuncionais ou polivalentes.

Um problema diferente foi encontrado na Firma $S$, que tinha ex. perimentado a multifuncionalidade. Categorias de trabalho especificas, tais como torneiro ou fresador, foram substituídas pelo termo genérico de operador de mdquina. Igualmente, a introdução de pequenas células e a operação de mais que uma máquina, bem como a integraçăo de tarefas de produção, controle de qualidade e de preparação, conduziram à ampliaçáo do trabalho desempenhado. Entretanto, devido à ampliaçăo das tarefas e também à alta precisáo requerida no trabalho dos operadores de máquina, a companhia abandonou os esforços para fazer rodízio de trabalhadores entre postos de trabalho. Ao invés de treinar os trabalhadores para usar máquinas diferentes, ela assumiu um esquema de treinamento que enfatizava o fato de desempenhar bem um trabalho, em vez de desempenhar diferentes trabalhos. Cada célula e cada máquina nas áreas de usinagem estavam sendo analisadas e normas técnicas e operacionais estavam sendo estabelecidas. Isto propiciaria uma base para o treinamento teórico e prático, com o trabalhador passando por um teste antes de ser certificado para trabalhar na máquina (a analogia usada foi a da habilitaçăo para dirigir). Nesta situaçáo, cada máquina teria um trabalhador principal certificado para a mesma e um ou dois outros trabalhadores como reserva. A movimentação de trabalhadores entre as minifábricas seria, então, quase inexistente, e o rodízio entre máquinas na mesma minifábrica seria excepcional ao invés de norma. A Firma $S$ parece estar indo na direção de um sistema que atenda as suas necessidades através de um processo de ensaio e erro característico de outras áreas de atividade estudadas na pesquisa.

A flexibilidade de uso do trabalho, portanto, depende de certo modo das características do processo de produção, e de como a produçáo está organizada. Pode ser muito comum quando grupos de trabalhadores operam como times - sendo responsáveis por uma área específica de produção e sendo treinados em algumas ou todas as tarefas da área. Enquanto todas as companhias na amostra tinham o poder para realocar trabalhadores entre tarefas, não houve evidência de que firmas estivessem assim procedendo sistematicamente. Embora a produção estivesse frequientemente sob o controle de um supervisor que tinha responsabilidade por todos os itens pertinentes à área (incluindo materiais, inspeção etc.) e que poderia realocar os trabalhadores quando requerido, não foi encontrado qualquer rodízio sistemático de tarefas. Em alguns casos, entretanto, os trabalhadores ausentes não eram substituí- 
dos, e os trabalhadores da área tinham que enfrentar as conseqüências (9).

Apesar destes casos de implementação de estratégias de JIT/TQC, aparentemente bem-sucedidos e de grande abrangência, um número maior de firmas, especialmente as firmas brasileiras, mostraram-se menos sistemáticas em sua adoçáo de novos métodos. Conquanto estas firmas tenham apresentado, algumas vezes, estatísticas impressionantes de reduçáo de perdas ou espaço de armazenagem economizado, os dados poderiam ser enganosos. Em alguns casos, os dados apenas se referem a áreas limitadas das fábricas. Em outras, ganhos significativos podem ser obtidos através da introdução de células de produçáo ou do redesenho de layouts, sem uma adoçáo completa de métodos de fluxo de produçáo ou qualidade na origem.

Apenas metade das companhias no estudo do IPEA havia formalizado por escrito políticas nas áreas de qualidade e produtividade, $\mathrm{e}$ o uso de indicadores para estabelecer metas, avaliar o progresso e localizar áreas problemáticas era muito limitado. Em parte, isto pode ter sido o resultado de as gerências estarem em um estágio inicial na implementaçāo de estratégias de produtividade e qualidade. Portanto, estavam apenas começando a entender as possibilidades abertas para elas e experimentando em uma base limitada para ver o que poderia funcionar bem. Entretanto, pode ser também o caso de que as firmas estavam dispostas a adotar as novas técnicas apenas em base um tanto quanto acidental - um pouco de SPC em uma parte da fábrica (especialmente em resposta a pressóes de clientes) (10), algum kanban limitado em uma outra parte - sem qualquer tentativa de aplicaçáo de princípios mais abrangentes em todo o processo de produçăo.

A principal razão para esta abordagem assistemática parece ser a falta de recursos gerenciais. A maioria das firmas na pesquisa estava transformando as fábricas existentes, ao invés de construir instalaçōes novas (greenfield). Introduzir sistemas JIT/TQC sistemáticos em companhias já estabelecidas implica um amplo espectro de mudanças. Estas podem incluir o reenfoque da produçăo da companhia em produtos $e$ processos-chave, e a restruturaçăo da administraçăo, de modo a reduzir o número de níveis hierárquicos e mudar as relaçóes entre os diferentes departamentos. Elas podem envolver, também, o melhoramento seletivo do equipamento, fazer com que os processos fiquem dentro de limites muito mais estreitos, e a modificação de procedimentos. As relaçōes com os fornecedores e os clientes podem também ter que mudar. As empresas no Brasil estáo tentando fazer tudo isto ao mesmo tempo, à medida que elas estáo enfrentando uma mudança no ambiente com- 
petitivo, uma recessão severa (desde 1990) e níveis muito altos de inflação (aproximadamente $20 \%$ ao mês em 1991-92).

Nestas circunstâncias não foi surpresa encontrar sinais de sobrecarga gerencial e, em alguns casos, uma reversão das tentativas anteriores para introduzir JIT/TQC. Na Firma D, por exemplo, um sistema kanban havia sido abandonado, sob a alegação da gerência de que a demanda irregular $\mathrm{e}$ instável das montadoras de veículos havia tornado o kanban inviável. Este ponto de vista era tanto um sintoma de uma ampla reversão de estratégia quanto uma declaração de causa e efeito. Enquanto outras firmas de componentes automotivos estavam indo em frente com JIT/TQC - as Firmas A, B e C estavam entre as mais avançadas, e Posthuma (1991) descreve experiências em uma série de outras empresas - a Firma D abandonou completamente o envolvimento dos trabalhadores com a qualidade, reclamando quanto à baixa qualificaçáo e educação, ao roubo por outras companhias de trabalhadores qualificados e à oposição de sindicatos. A companhia estava considerando a automaçáo como uma alternativa ao investimento em mão-de-obra, ao invés de como um complemento à mesma. Em grande parte, esta reversão na política foi resultado da recessão, a qual levou as companhias a se concentrarem nos cortes de custos e na sobrevivência de curto prazo. Em 1991, a companhia fechou seu departamento de treinamento e demitiu o gerente por ele responsável. Embora a recessáo e a competiçáo possam forçar as companhias a mudar e inovar, podem também paralisar a gerência e trabalhar contra investimentos em qualidade e produtividade, cujo retorno pode ser plenamente realizado apenas a médio prazo. Esta paralisia da gerência foi observada em companhias menores e em grandes empresas de propriedade familiar, que careciam de uma estrutura de administraçăo forte e possivelmente de recursos financeiros, que poderiam permitir que elas enfrentassem a recessāo. Em duas companhias familiares, as Firmas $\mathrm{D}$ e $\mathrm{L}$, foram observados também sinais de divisóes na família quanto à estratégia da companhia, o que tendia a minar o movimento na direção dos sistemas JIT/TQC.

Os resultados da pesquisa do IPEA e de outros estudos no Brasil (Lima, 1989; Roese, 1992; Posthuma, 1991) mostram claramente que é possível para as empresas realizar inovaçóes na área de JIT/TQC. Algumas das melhorias foram mantidas por um período de tempo e se generalizaram pelas fábricas. Elas não se constituem em ganhos rápidos que se perdem conforme o entusiasmo se esvanece e os sistemas de produçáo lentamente retornam aos padróes de operação adotados de longa data. Entretanto, os ganhos duradouros requerem uma contribuição intensiva e persistente da gerência. Os processos de produção precisam ser entendidos, analisados e colocados sob controle, o que 
envolve atividades intensivas de engenharia e capacitação tecnológica em nível da firma. A média gerência e os supervisores têm de ser reorientadas, assumindo novas tarefas e permitindo que outras tarefas sejam eliminadas ou transferidas a outros (11). Os trabalhadores têm que ser motivados e treinados. Os sistemas JIT/TQC não são uma fórmula mágica que pode propiciar grandes ganhos com pouco investimento.

\section{O Impacto dos sistemas JIT/TQC nas relações trabalhistas no Brasil}

Desde um longo tempo, as relaçōes trabalhadores-gerência no Brasil têm sido pobres. No decorrer dos anos 70 , as taxas de rotatividade de pessoal eram altas, devido às políticas das empresas de contratar-edemitir e devido à movimentaçăo dos trabalhadores de companhia em companhia em busca de melhores salários ou oportunidades de promoção. $O$ desenvolvimento de um movimento trabalhista mais forte após as ondas grevistas de 1978-79 exacerbou os problemas. As gerências geralmente resistiam à tentativa dos sindicatos para desenvolver organizaçôes em nível de fábrica, e a crise econômica contínua conduzia a ondas de demissão recorrentes, a erosão dos salários pela inflação em rápida aceleração, e a pacotes governamentais intermitentes com medidas contra a crise, as quais tendiam a incluir o congelamento de salários ou mesmo sua redução. Isto piorou significativamente o clima das relações industriais e impediu que um relacionamento mais conciliatório entre a gerência e os trabalhadores emergisse. No decorrer dos anos $\mathbf{8 0}$, as taxas de rotatividade caíram, parcialmente devido à recessão (que reduziu a rotatividade motivada pelo trabalhador), parcialmente por uma atividade maior dos sindicatos, e parcialmente devido à introduçáo de novas tecnologias em alguns setores da indústria (Schmitz \& Carvalho, 1988). Mesmo assim, o sistema brasileiro de relaçóes industriais permaneceu em um estágio em que o nível de compromisso mútuo entre gerência e trabalhadores era baixo. $O$ estilo de administração, que havia sido claramente autoritário (Humphrey, 1982), foi apenas ligeiramente modificado. As companhias continuavam a ver a mão-de-obra como dispensável e a principal função da gerência como sendo a de controlar.

Neste clima, como é possível para as empresas introduzir sistemas que aparentemente necessitam de certo grau de cooperação entre a gerência e os trabalhadores? Os resultados da pesquisa do IPEA sugerem que o envolvimento do trabalhador foi obtido através de uma barganha implícita entre a gerência e os trabalhadores, a qual está centrada na estabilidade no emprego, nos salários e nos estilos de supervisáo. 
A fim de superar a apatia e a resistência do trabalhador, as gerências foram forçadas a fazer uma ruptura com o passado. Em alguns casos, esta ruptura e um nopo comego sáo explicitamente anunciados aos trabalhadores como a primeira etapa na direção da obtençáo da concordância com os novos métodos. Um passo fundamental neste sentido é mudar a política com relaçáo à estabilidade no emprego. $O$ estudo de Lima (1989) sobre sete companhias introduzindo o sistema Just-inTime no sul do Brasil observa que em uma série de casos, o compromisso com a estabilidade no emprego foi um elemento-chave na definição da passagem para uma nopa era das relaçóes entre a empresa e seus funcionários (Lima, 1989:57-58,90,105). Em alguns casos, incluindo as Firmas $\mathrm{S} \mathrm{e} \mathrm{V}$ da amostra do IPEA, o emprego sazonal terminou. No caso da Firma $S$, a companhia substituiu a contrataçáo sazonal por um sistema de trabalho de semanas de quatro dias no veráo e sábados extras no inverno. Um compromisso com a estabilidade no emprego foi também efetuado por outras companhias. No caso da Firma G, a gerência retirou o direito dos supervisores para demitir funcionários e colocou sobre eles o ônus de melhorar o desempenho e as atitudes dos trabalhadores. No caso da Firma J, nenhum funcionário foi demitido em um período de seis semanas, durante o qual a fábrica ficou sem nenhum trabalho a executar. Em contraste com as práticas anteriores, as empresas começaram a adotar medidas tais como acabar com as horas extras, diminuir a semana de trabalho, antecipar as férias anuais e favorecer a licença voluntária dos trabalhadores (remunerada ou náo) antes de cortar a força de trabalho. Nos anos 70 era muito comum encontrar demissóes sendo feitas em períodos durante os quais se estava trabalhando em regime compulsório de horas extras (Humphrey, 1977).

Esta nova atitude quanto à estabilidade no emprego gerou efeitos claros, como pode ser visto na tabela 2 . Em quatro firmas dentre 18 , as taxas de rotatividade estavam ao redor do nível de $5 \%$ anual e, em cinco outras, e, em aproximadamente $15 \%$, o que é baixo para os padróes brasileiros. Este padrão de estabilização do trabalhado pode ser visto claramente como um acordo implícito entre gerência e trabalhador. $\mathrm{Da}$ parte da gerência, não há qualquer garantia explícita de estabilidade de emprego - apenas uma promessa, e em algumas companhias ela é condicional. Os trabalhadores que não desempenham bem suas funçóes ou não se comprometem com o sistema ainda são demitidos, $e$ isto tem ocorrido. No caso da Firma G, o compromisso para estabilizar a máode-obra náo seria honrado se os trabalhadores entrassem em greve, e a gerência declarou que tirava vantagem de ocasióes em que alguns trabalhadores apoiavam greves convocadas pelo sindicato (organizadas em nível da cidade) para demitir ativistas e também para se livrar de trabalhadores com baixo desempenho (12). 
Taxas de Rotatividade, 1990/1991: 18 companhias.

Taxa de Rotatividade(a)

Número de Companhias

\begin{tabular}{ll} 
1. $3-6 \%$ & 4 \\
2. 13-18\% & 5 \\
3. Mais de $30 \%$ & 4 \\
$\begin{array}{l}\text { Fatores especiais em 1990/91 ou nenhum } \\
\text { dado disponível }\end{array}$ & 5 \\
\hline
\end{tabular}

Observaçăo:

(a) Saldas por ano como percentagem da média mensal de contrataçáo. Taxa para 1990, ou primeira metade de 1991 se as figuras de 1990 não estiverem disponfveis ou afetadas por fatores especiais.

Fonte: Fleury \& Humphrey (1992:56).

Do ponto de vista da mão-de-obra, o envolvimento estava associado com um claro, embora não garantido, compromisso com a estabilidade de emprego. Indivíduos podem ser demitidos por razóes disciplinares, ou não ser substituídos se a produtividade estiver aumentando mais rápido que a produçăo, mas as demissóes devem ser evitadas. Entretanto, uma série de companhias fez reduçóes na mão-de-obra em 1990-91, como pode ser visto na tabela 2. Isto foi resultado da recessáo profunda - em 1990 o GDP brasileiro caiu em 4\%, e muitas companhias sofreram quedas severas na demanda por seus produtos, bem como condiçóes de comércio geralmente adversas (altas taxas de inflação e de elevadas taxas de juros reais etc.). Gerentes de algumas companhias que tinham demitido grande número de trabalhadores reportaram uma diminuiçäo clara no compromisso assumido pelo trabalhador com os novos sistemas. Isto foi expresso pelo declínio no uso de esquemas de sugestóes, uma diminuiçáo de atividades de pequenos grupos e quedas nos níveis de qualidade. A gerência fez uma ligação direta entre as demissões e estes efeitos.

A estabilidade foi um ponto de partida crucial para a política de aumento no envolvimento, mas não foi suficiente por si só. Os trabalhadores no Brasil esperam ver algum retorno por seu envolvimento. Se este envolvimento aumenta a sua produtividade, entáo eles devem ser beneficiados. As companhias estavam fazendo dois esforços nesta área. A primeira foi relacionar os bônus de salário diretamente com o desempenho da companhia, como descrito para o caso da Firma $S$, na 
seçáo anterior. Estes esquemas de bônus, sejam ligados à obtenção de metas departamentais específicas como no caso da Firma $S$, ou calculados com base no desempenho geral da companhia, como na Firma G, podem se tornar bastante populares no Brasil. No momento, seu uso é limitado pela legislação trabalhista, que permite aos trabalhadores reivindicarem que bônus regulares sejam incorporados aos seus saláriosbase. As companhias temem que o pagamento de bônus possa conduzir a reivindicaçốes para tal incorporação, e isto tem, até agora, restringido seu uso grandemente (13).

A segunda estratégia observada pelas companhias foi a oferta de maiores oportunidades de treinamento e promoçōes, já discutidas no tópico anterior. Os trabalhadores de produçáo dáo grande valor ao treinamento e oportunidades de promoçáo no Brasil, porque as diferenças salariais entre trabalho não-qualificado, semi-qualificado e qualificado são muito grandes. Um operador de máquina semi-qualificado pode ganhar de $60 \%$ a $100 \%$ a mais de salário que um trabalhador não-qualificado na mesma companhia. $O$ diferencial de salário por hora entre o trabalhador manual de nível mais inferior e o de maior nível (excluindo chefes e supervisores), em uma importante fábrica automobilística, era maior que 3,7:1 em 1985. Ao mesmo tempo, a estabilidade de emprego está fortemente associada com a promoção e o treinamento (14). Uma avaliaçáo adequada de como os novos sistemas ocupacionais operam na prática necessitaria de um tipo de análise detalhada que não foi possível realizar na pesquisa do IPEA. Existe sempre o risco de que as companhias venham a criar expectativas que não possam cumprir, como parece ter sido o caso na fábrica da Ford, em Hermosillo, México (Carrilo; Micheli; Ramirez, 1990). Como foi observado no item anterior, os gerentes em algumas companhias enfatizaram as desvantagens deste tipo de sistema. Além disso, a reduçáo dos níveis hierárquicos e a unificação de títulos de funçóes não envolve, necessariamente, a multiespecialização ou a adoçăo de tarefas múltiplas, se os trabalhadores não se movimentam entre diferentes funçóes.

A terceira maneira pela qual as empresas buscaram o envolvimento dos trabalhadores diz respeito às relaçóes entre trabalhadores $\mathrm{e}$ gerência. Isto não é tão fácil de identificar, mas pode ser uma parte importante do estímulo aos trabalhadores para se comprometerem com os novos padróes de trabalho. Os trabalhadores no Brasil estáo acostumados a ser desvalorizados por seus empregadores. A política de contratar-e-demitir, a gestáo autoritária e a divisão detalhada do trabalho eram sinais desta desvalorizaçăo. A introdução de SPC, Just-in-Time, atividades de pequenos grupos e esquemas de sugestōes colocaram grande ênfase na contribuição que os trabalhadores podem propiciar. 
Isto, por si só, pode ser um ganho - na auto-estima e no sentimento de se estar desempenhando um trabalho significativo. Novos padróes de trabalho podem conduzir a uma mudança nos estilos de supervisão, do autoritário para o técnico. Certarnente, algumas gerências sugeriram que o trabalho dos supervisores foi alterado, e em algumas companhias novos supervisores foram contratados.

O sentimento de ser levado a sério e respeitado pode ser aumentado ainda mais por pequenas melhorias nas condiçōes e nas práticas de trabalho, tal como a melhoria nas áreas de lazer para café e a implantação de caixas automáticos nos locais de trabalho, bem como as inovaçóes japonesas mais óbvias, tal como ginástica e painéis de estado de espirito (15). Embora isso possa ser considerado como secundário, e possa em algumas circunstâncias ser rejeitado pelos próprios trabalhadores, é indicativo de uma mudança de atitude. Conforme observa Rodrigues (1991), mesmo trabalhadores que eram geralmente hostis ao JIT na Firma V, responderam positivamente à introdução de áreas de café que podiam ser decoradas pelos trabalhadores com plantas e tanques de peixe e providas de material para leitura.

A troca implícita entre gerência e trabalhadores - aceitação de novas práticas de trabalho em retorno por alguma estabilidade no emprego, a possibilidade de salários melhores e uma atmosfera melhor no local de produção - propicia ganhos reais para os trabalhadores. Em países com um movimento trabalhista mais forte, alguns destes ganhos foram obtidos durante o fordismo, mas este não é o caso no Brasil. Entretanto, não é possível chegar a uma avaliação geral do impacto dos sistemas JIT/TQC para os trabalhadores nas fábricas estudadas. Uma razão para isto é, simplesmente, que o estudo do IPEA não foi suficientemente profundo quanto ao trabalho diário nas fábricas estudadas. Sua informação foi obtida da gerência e é, inevitavelmente, parcial. Berggren (1991) aponta corretamente para as limitaçōes de informaçóes da gerência sobre mudanças nos ambientes de trabalho. Estas limitaçôes são ainda mais importantes se, como foi argumentado na introdução, o impacto de JIT/TQC sobre a mão-de-obra é complexo e matéria de controvérsia. Existem, entretanto, mais duas razóes substantivas para sermos cuidadosos ao prover respostas definitivas para questóes sobre o impacto geral de JIT/TQC para o trabalho. Elas dizem respeito à complexidade do impacto de JIT/TQC sobre o trabalho, em quaisquer circunstâncias, e nas circunstâncias especiais de sua implantação no Brasil.

Posiçóes altamente contrastantes sobre o impacto de JIT/TQC para o trabalho já foram mencionadas na introduçáo a este texto. $\mathrm{Na}$ literatura, argumenta-se freqüentemente que um padráo específico de 
organização da produção possui conseqüências inerentes e necessárias para o trabalho - para o bem e para o mal. JIT/TQC (ou produção enxuta, ou especializaçăo flexível) é caracterizado como um modelo único com um conjunto definido de consequiências para a mão-de-obra. A evidência empírica é muito mais variada. Conforme observa Posthuma, esta recusa da evidência empírica para se ajustar à teoria pode ser justificada pelo tratamento dos casos divergentes como exceçóes de curto prazo em relação a uma tendência de longo prazo, ou pela identificação das empresas que não estáo de acordo com o modelo como perdedores sem viabilidade a longo prazo (1991:11). Embora seja bem possivel que as companhias que tentaram implementar JIT/TQC sem treinamento sistemático têm grande probabilidade de falhar, parece existir uma variedade de caminhos nos quais os princípios JIT/TQC podem ser operacionalizados, e estes possuem conseqüências diferentes para a máo-de-obra. Para tomarmos um exemplo, o autor visitou recentemente uma fábrica no País de Gales que era, sob todos os aspectos, altamente enxuta. Ela possuía um sistema de baixo estoque que produzia produtos de alta qualidade, e a matriz japonesa parecia satisfeita com a mesma. Entretanto, a companhia atingiu produção flexível (vários produtos e mudanças entre eles), fluxo de produçăo (estoques intrafábrica de náo mais que quatro horas) e alta qualidade na ausência de círculos de QC, esquemas de sugestáo, rodízio de tarefas, multiqualificação ou multitarefas sistemáticas, SPC, e um sistema pull de produção. A companhia possuía supervisores responsáveis por tudo em suas áreas e o direito de realocar trabalhadores entre tarefas, mas as características principais da fábrica que asseguravam seu sucesso parecia ser o layout, o planejamento da produçáo, atenção aos detalhes e o rastreamento de todas as falhas de.qualidade até suas origens.

O exemplo desta fábrica do País de Gales é apresentado porque ele mostra o quanto sistemas que oferecem elementos de JIT/TQC podem variar. A fábrica era, principalmente, mas não inteiramente, uma fábrica de montagem produzindo periféricos para computadores. Ela enfrenta problemas diferentes daqueles vistos na indústria automotiva, e encontra soluçōes diferentes. Um estudo recente de transplantes japoneses nos Estados Unidos da América mostrou que muitas das práticas associadas com companhias japonesas; tais como o trabalho em grupo, rodízio entre as funçōes, círculos de QC e kaizen são encontradas em maior extensão em transplantes automotivos do que em transplantes eletrônicos (Kenney \& Florida, 1992:41). Mesmo se a produçáo enxuta fosse um sistema novo de produção que substituísse a produção em massa, entáo o nível de variação encontrado no mesmo acabaria com generalizaçóes quanto ao seu impacto sobre a mão-de-obra. Também argumen- 
tamos que JIT/TQC é um sistema com impactos complexos na måode-obra. Ele pode implicar trabalho mais variado e interessante, embora nem sempre. Pode também prover a oportunidade para participar de grupos de melhoria ou círculos de qualidade, embora nem todos os sistemas JIT/TQC os utilizem. Mas ele também propicia a possibilidade de um controle maior. Os sistemas JIT/TQC são inerentemente mais enxutas na localização de deficiências no sistema e na designação de obrigaçóes diretamente aos trabalhadores e aos grupos.

No caso das companhias brasileiras, existem também circunstâncias específicas que envolvem a maneira pela qual JIT/TQC afeta a mãode-obra. Em uma pesquisa recente da literatura brasileira sobre este tópico, $M$. Leite (1992) percebeu que os observadores geralmente concordavam que durante a maior parte dos anos 80 , as companhias tentavam implantar estas técnicas como círculos QC, SPC e kanban sem alterar fundamentalmente sua postura com relação ao trabalho, que permaneceu autoritária. Era observável que tentativas para emular os japoneses não envolvia aumento no treinamento ou estabilidade no emprego. Como Leite observa, existem sinais de que isto está mudando. Mudanças com um alcance muito maior têm sido observadas por alguns autores (Fleury \& Humphrey, 1992; Gitahy \& Rabelo, 1991), mas existe, ainda, pouca evidência sólida de que estas mudanças estão afetando a experiência diária de trabalho. É claro que mais pesquisas precisam ser feitas.

As gerências no Brasil possuem uma posição relativamente forte a partir da qual buscam o ajuste do trabalho aos novos métodos de produçáo. Como já havia sido observado, eles possuem certos ganhos para oferecer aos trabalhadores nas áreas de estabilidade de emprego, salários e supervisores. Ao mesmo tempo, eles mantiveram a liberdade para demitir trabalhadores, $\mathrm{e}$ isto não está sujeito a restriçóes legais, exceto no caso de representantes sindicais e mulheres grávidas. Acrescido a isto está o fato de que os sindicatos possuem pouca penetração em nível de fábrica. Nenhuma dentre as gerências na amostra havia negociado com os sindicatos quanto à introdução dos novos métodos, e a manutenção dos sindicatos fora das fábricas era um objetivo-chave dessas gerências.

Apesar dessas vantagens, as gerências mostram sinais de cautela. No caso da Firma V, por exemplo, os gerentes mostraram mais paciência do que teria sido observado nos anos setenta quando encontraram resistência à sua demanda de que os trabalhadores fossem responsáveis pela limpeza das áreas ao redor de suas próprias máquinas, e que intervalos de 15 minutos para café fossem abandonados em favor de intervalos informais nas áreas de descanso instaladas perto das linhas de pro- 
dução (Rodrigues, 1991). Os trabalhadores que quebravam as vassouras fornecidas para limpeza recebiam uma nova vassoura todos os dias até que a resistência parou, e a oposição do turno da noite em abolir os intervalos para café foi tolerada até que o declínio na produção resultou no término do turno da noite (16). Da mesma forma, na Firma S, uma nova estrutura ocupacional e salarial foi introduzida lado a lado com a reorganizaçăo da produçăo, mas a gerência deixou claro que os trabalhadores mais velhos não seriam forçados a mudar para o novo sistema se eles náo desejassem fazê-lo. $\mathrm{Na}$ prática, as desvantagens de permanecer fora do novo sistema persuadiram a maioria dos trabalhadores a aceitá-lo, mas a cautela da gerência ficou bastante clara (Roese, 1992). Os comentários de Roese sobre um proponente de IIT/TQC no Rio Grande do Sul, o qual infelizmente não pôde ser incluído na amostra, parecia se aplicar amplamente: "A companhia adotou atitudes que tentaram mostrar o valor que ela depositava nos trabalhadores e seu respeito quanto à dignidade de seus funcionários. No entanto, a maneira como isto é feito está carregada com aspectos que constrangem o comportamento dos trabalhadores, tais como critérios de treinamento e de promoçáo que levam em conta o comportamento dos trabalhadores e a apresentaçáo de um painel proeminente com o nome, a fotografia e o motivo da ausência dos trabalhadores ao trabalho" (1992:159).

O grau de cautela mostrado pelas companhias e sua relutância em forçar muito a situaçáo parece ser o resultado de quatro fatores principais. O primeiro é que a gerência está ansiosa para manter os sindicatos fora de suas fábricas. A lei concede certos direitos aos sindicatos, incluindo a representaçáo exclusiva, e um papel formal na barganha coletiva, que acontece principalmente a nível de indústria e por região (por exemplo, metalúrgicos em um determinado município). Entretanto, os sindicatos náo possuem direitos para intervir a nível de fábrica ou negociar diretamente com companhias individuais. As gerências estáo ansiosas para que esta posição seja mantida, em parte porque os sindicatos têm sido hostis aos métodos japoneses, e em parte devido à instabilidade econômica e queda nos salários reais, os quais tornaram as relaçóes gerência-trabalhadores difíceis na década passada. As gerências associam a atividade dos sindicatos com militância e oposiçăo a mudança. Eles temem a militância sindical, e estão ansiosos para esvaziar previamente as demandas dos sindicatos oferecendo salários e condiçóes que sejam atraentes aos trabalhadores. De fato, uma das motivaçóes para a adoçáo pelas gerências de Círculos de Qualidade, Grupos de Melhoria, relaçóes melhores e mais abertas entre gerências e trabalhadores (acesso portaaberta com a gerência superior, caft' matinal com o chefe, registros do estado de espírito dos trabalhadores, ginástica coletiva etc.) é precisa- 
mente descobrir o descontentamento antes dos sindicatos poderem se mobilizar sobre $o$ assunto. Um regime relativamente (e apenas relativamente) năo opressivo pode ser um preço que tem que ser pago para manter os sindicatos distantes.

Um segundo fator é que as companhias estão preocupadas quanto à rotatividade iniciada pelos trabalhadores. Os trabalhadores do sexo masculino são capazes de mudar de companhia para companhia sem sofrerem uma perda salarial substancial. No caso de trabalhadores qualificados, as companhias estão, freqüentemente, prontas a roubar trabalhadores de outras oferecendo melhores salários. Enquanto as companhias maiores tentam limitar a rotatividade pagando salários relativamente altos, o medo da rotatividade é ainda um constrangimento, $e$ isto pode inibir aumentos na intensidade do trabalho. Este problema é exacerbado pela eventual escassez de trabalhadores. Como já observado, os níveis de educação são baixos. As companhias introduzindo os métodos japoneses querem empregar trabalhadores com pelo menos o primeiro grau completo (8 anos), e o sistema educacional náo está provendo este tipo de trabalhadores em quantidades adequadas.

Em terceiro, as fábricas estudadas no Brasil eram todas instalaçōes antigas. Isto não é surpreendente, visto que tem havido relativamente pouco investimento das companhias brasileiras ou do exterior, na última década. Portanto, as gerências têm passado pelo processo de mudança de padróes de trabalho com as forças de trabalho existentes. Isto, certamente, coloca limites naquilo que pode ser atingido.

Finalmente, deveria ser lembrado que as gerências estão ainda no processo de aprender como operar os sistemas JIT/TQC e não de obterem controle total dos mesmos. Elas estão examinando o que são capazes de fazer e ainda não entenderam completamente os resultados em termos das relaçóes trabalhador-gerência. A cautela com a qual eles estão sendo aplicados pode ser um efeito do processo de aprendizagem que está em andamento. Em particular, poucas companhias na amostra haviam incorporado avaliaçő́es sistemáticas em seus sistemas de promoçóes e treinamento e não tinham, portanto, desenvolvido o tipo de controle sobre o trabalho descrito por Ogasawara (1992). Ainda não está claro se a avaliação de pessoal será desenvolvida extensivamente pelas empresas no Brasil.

\section{O Brasil e o Terceiro Mundo em industrialização}

O que a experiência do Brasil nos diz sobre as perspectivas ou possibilidades para a implantaçáo de JIT/TQC em outros países do Terceiro Mundo em industrializaçáo? O primeiro ponto claro é que a 
implantaçáo de sistemas JIT/TQC é possível em países de Terceiro Mundo, mas não é fácil. Algumas companhias de ponta $\mathrm{em}$ muitos países serão capazes de introduzir alguns elementos de JIT/TQC mas é muito mais difícil que JIT/TQC sejam introduzidos amplamente na produção. A amplitude de sua introdução dependerá, quase que certamente, de políticas governamentais (local e regional, bem como nacional). No caso do Brasil, empresas de ponta conseguiram introduzir JIT/TQC, apesar das falhas governamentais em política macroeconômica e antes que o PBQP tivesse tido tempo para realizar um impacto. Não pode haver dúvida, entretanto, de que um ambiente favorável e o apoio governamental ajudaráo muito a ampliar a adoçáo de JIT/TQC. A evidência do Brasil também mostra que a política para a educaçáo e o treinamento podem ser tão importantes quanto a política para o comércio e a indústria. JIT/TQC é intensivo em qualificações relacionadas com a engenharia e a gerência e nas qualificaçốes derivadas da educaçáo básica. A implantaçáo bem-sucedida de JIT/TQC necessita, pelo menos, de trabalhadores com educação básica (aqueles com alfabetização e educaçáo primária), identificados por Wood (1991:27-28) como sendo essenciais para uma estratégia bem-sucedida de exportaçáo da produçáo, e pode necessitar de trabalhadores com educação em nível secundário para a integração extensiva de tarefas de qualidade e manutenção nos trabalhos de produção, e para a melhor utilização de círculos de QC e outras atividades de melhoria.

Existem também indicaçóes claras de que a implantação de JIT/TQC terá impactos bastante variados sobre o trabalho. As diferenças entre as indústrias automobilística e eletrônica já foram observadas por Kenney \& Florida (1992). As fábricas no estudo do IPEA eram todas estabelecidas em locais antigos e eram, principalmente, típicas de indústrias verticalmente integradas, estabelecidas por um regime de industrializaçáo de substituiçáo de importaçóes. Em outros países, onde os processos de produção são menos integrados verticalmente, ou onde novas fábricas estão sendo instaladas, o impacto de JIT/TQC para a máo-de-obra pode ser bem diferente. Um exemplo seria o Norte do México, onde os sistemas JIT/TQC foram largamente desenvolvidos dentro e entre as companhias, pelas companhias automobilísticas norte-americanas que haviam construído fábricas novas, orientadas para exportação (Carrilo; Micheli; Ramirez, 1990; Shaiken, 1990). O impacto será diferente, novamente, nas fábricas eletrônicas do Leste e Sudeste da Ásia.

O caso do Brasil também mostra que as implicaçóes da implantação de JIT/TQC para as relaçōes industriais são imprevisíveis. Em vista do histórico de relaçóes industriais pobres no Brasil, e da oposiçáo 
dos sindicatos a muitos dos elementos da produção enxuta, é talvez surpreendente descobrir que as companhias enfrentaram pouca oposiçáo. Em contraste, a Ford encontrou uma série de problemas em Hermosillo, no Norte do México, apesar de construir uma fábrica nova, em local escolhido, em parte, por apresentar uma máo-de-obra dócil (17). Similarmente, as conseqüências de introduzir JIT/TQC em um ambiente trabalhista volátil tal como aquele encontrado na Coréia do Sul são extremamente imprevisíveis. Entretanto, as companhias que usam JIT/TQC irão, certamente, tentar limitar as possibilidades de ação coletiva, limitando o poder dos sindicatos e, simultaneamente, tentar aumentar a disciplina exercida sobre trabalhadores individuais e grupos de trabalho no local de trabalho. Protestos coletivos e individuais são inimigos de JIT/TQC.

Finalmente, deve-se lembrar que estudos em nível de fábrica não podem prover dados completos sobre o impacto de JIT/TQC para o trabalho. JIT/TQC é parte de uma estratégia mais ampla de reenfoque da produção, redefinição das linhas de produto e das relaçóes com os fornecedores e clientes. $\AA$ medida que os sistemas JIT/TQC podem envolver subcontratação de partes do processo de produção, a criaçáo de fornecedores especializados para serviços específicos e a imposiçăo (ou negociação) de novos padrōes aos fornecedores já estabelecidos, a implantaçăo de JIT/TQC pode ter ramificaçóes fora das fábricas na qual tais sistemas são centrados. Resta observar como os benefícios e desvantagens de produção enxuta afetam, para a frente e para trás, as cadeias de fornecimento e distribuiçáo.

\section{Notas}

10 International Motor Vehicle Project (IMVP), liderado pelo Massachussets Institute of Technology, foi um programa de pesquisa cujas principais recomendaçóes săo apresentadas em Womack, Jones \& Roos (1990).

20 termo produção enxuta (lean production) é bastante identificado com o projeto IMVP. Neste trabalho, o termo JIT/TQC será usado. Esse termo é mais estreitamente enfocado na produçáo, e te menos pretensioso quanto a ser um modelo ou um novo estágio do desenvolvimento industrial.

3 Oliver \& Wilkinson (1988) usam o termo dependencia reversa para denotar os meios pelos quais as companhias buscam minimizar a vulnerabilidade dos sistemas de baixo estoque a interrupçóes, criando mecanismos que reduzem o potencial de conflito e estabelecendo controle tanto sobre os trabalhadores quanto sobre os fornecedores externos. Esta noçäo poderia ser desenvolvida para examinar a linha limite entre consentimento e compulsăo.

4 Para uma análise dos fluxos de comércio que enfatiza a formaçáo de qualificaçōes e a educaçăo, veja Wood (1991). 
5 Estudo realizado por um grupo coordenado por Fleury \& Humphrey pam o Instituto de Pesquisa Económica Aplicada (IPEA) em Brasflia. Neste artigo, esse estudo será referido como a pesquisa do IPEA ou estudo do IPEA. Os detalhes sobre as firmas da amostra são apresentados na mbela 1. Para informaçöes adicionais do projeto, ver Fleury \& Humphrey (1992).

6 Não está absolutamente claro o quão confí́veis săo estes dados. Conforme Oliver (1990:34) observou, JT pode se referir a enorme variedade de téenicas.

7 As letras usadas aqui para referéncia às firmas săo as mesmas usadas em Fleury \& Humphrey (1992).

8 Humphrey (1987:43-46) mostra como, no caso de trabalhadoras do sexo feminino ma produgão, o uso de categorias ocupacionais amplas e únicas mis como montudora e avistente de produyfuto cobrindo de 60-85\% de todas as trabalhadoras horistas poderiam ser combinadas com uma divisão detalhada de măo-de-obra ao longo das linhas tayloristras.

9 Bxiste bastante confusäo na literatura sobre o que constitui trabalho de grupo. Grupos de trabalhadores referidos como times podem ter estruturas e responsabilidades bastante diferentes. As decisóes sobre o rodfrio de funçбes, e até quanto os grupos são considerados responsáveis por seus membros, são áreas cruciais de diferença.

10 Veja Posthuma (1991) para uma referencia de como algumas companhias brasileiras de pecas implementaram o SPC de modo a satisfazer as demandas de seus clientes montadores de veículos, apesar de não enxergarem tal fato como um meio para localizar problemas de qualidade e resolve-los. Este tipo de problema significa que os dados oferecidos por Ferraz, Miles \& Rush (1992), já citados, necessitam ser interpretados com cautela.

11 A oposiçăo d̀ mudança, por parte da geréncia média e dos supervisores, năo foi um obstáculo interno citado com freqüencia.

12 Lima (1989:58) cita o caso de uma companhia que iniciou o processo de mudanga atravts da demissäo de 200 trabalhadores potencialmente hostis.

13 Um aspecto adicional desta relaçáo entre envolvimento e recompensa té a utilizaçäo ampla de premios (incluindo dinheiro) para esquemas de caixa de sugestōes e projetos de pequenos grupos. As recompensas estão longe de ser meramente simbblicas, como é usualmente o caso no Japăo.

14 Trabalhadores especializados, em contraste, enxergam a introduçäo de grupos de manutençăo flexfveis, flexibilidade funcional na ferramentaria e inovaçöes similares como um fato que corrói as distinçбes das especializaçóes e tanto os obriga a fazer trabalhos menos especializados juntamente com seu trabalho normal, o que consideram como humilhante, ou os obriga a executar trabalhos mais especializados, ao que resistem em fazer se nāo existir uma elevaçăo salarial equivalente (Leite, 1990). Trabalhadores especializados podem prover mais resisténcia a mudanças organizacionais.

15 O nome de todos os trabalhadores estri em um painel, e cada um deles deve indicar como se sente diariamente - bem, ok, ou mal. Os gerentes ou supervisores devem inquirir se um trabalhador indicar mul por mais de um dia subsegüente. $\mathrm{Na}$ Companhia J, que tinha ido além na adogáo destns práticas japonesas, o gerente de fábrica cstava particularmente orgulhoso e entusiasmado sobre a maneira pela qual os paintis de es- 
tado de esperito tinham permitido à gerência localizar e ajudar a resolver problemas externos ao local de trabalho, que estivessem afetando os trabalhadores.

16 A Companhia $\mathrm{V}$ foi uma daquelas cujas políticas foram minadas por uma queda catastrófica nas vendas após 1989. Essa queda foi parcialmente resultado da recessáo na economia brasileira e, parcialmente, das restriçōes governamentais sobre créditos para agricultura.

17 Carrillo, Micheli e Ramirez (1990) discurem com algum detalhe as razóes pelas quais a Ford está localizada em Hermosillo e os conflitos na fábrica.

\section{Referências bibliográficas}

AMSDEN, Alicee. Asia's mext giant. New York, Oxford University Press, 1991.

BERGGREN, Christian. Are they unbeatable: report from a field trip to study transplants, the Japanese owned auto plants in North America. Trabalho apresentado no Simpósio Internacional The Production Strategies and Industrial Relations in the Processo of Internationalization, Sendai, Japan, 1991.

CARRILLO, Jorge; MICHELI, Jordy; RAMIREZ, Miguel. Organización flexible capacitación en el trabajo: un estudio de caso. Cidade do México, Friedrich Ebert Stiftung, Documentos de Trabajo, no 30, 1990.

DELBRIDGE, Rick; TURNBULL, Peter; WILKINSON, Barty. Pushing back the frontiers: management control and work intensification under JTT/TQM factory regimes. New Technology, work and employment, (próximo).

FERRAZ, Joăo Carlos; RUSH, Howard; MILES, Ian (1993). Development, technology and flexibility. Londres, Routledge.

FLEURY, Afonso, \& HUMPHREY, John. Recursos Humanos e a difusão de adaptaçăo de novos métodos de qualidade no Brasil. Brasilia, IPEA, Relatorio de discussto, 1992 (próximo). Uma versāo revisada deste texto será publicada em Inglês em 1993 como um IDS Research Report.

GITAHY, Leda \& RABELO, Flávio. Educaçăo e desenvolvimento tecnológico: o caso da indústria de autopeças. DPCT/IG/UNICAMP, Textos para Discussä̃o 11, 1991.

HOFFMAN, Kurt, \& KAPLINSKY, Raphael. Driving force. Boulder, Westview, 1988.

HUMPHREY, John. The development of industry and the bases for trade unionism: a case of study of car workers in Săo Paulo, Brazil (Tese de doutoramento não publicada), University of Sussex, 1977.

HUMPHREY, John. Capitalist control and workers struggle in the Brazilian auto industry. Gráfica da Universidade de Princeton, 1982.

HUMPHREY, John. Gender and pork in the Third World. Londres, Tavistock, 1987.

JONES, Dan. Beyond the Toyota production system: the era of lean production. Trabalho apresentado na $5^{2}$ Conferencia Internacional de Gerenciamento de Operafóes, Warwick, 1990. 
KENNEY, Martin \& FLORIDA, Richard. Japanese-style management in three U.S. transplant industries: autos, steel and electronics. Trabalho apresentado no seminário Japanese Management Styles: an international comparation perspective. School of Business, University of Wales, College of Cardiff, 1992.

LEITE, Elenice. Diagnóstico da área da mecânica, Säo Paulo, SENAI, Divisáo de Pesquisas, Estudos e Avaliação, Stries Especiais de Estudo, 1990.

LEITE, Márcia. Modernização tecnológica e relaçôes de trabalho no Brasil: notas para uma discussão. Trabalho apresentado no Seminário Trabalbo e Educagato. São Paulo, Fundação Carlos Chagas, 1992.

LIMA, Irê. Andtise das consequitncias da utilizagto das filosofias e thonicas japonesas de gestito da producfato sobre o rendimento das empressas (dissertaçäo de mestrado). Universidade Federal do Rio Grande do Sul, 1989.

OGASAWARA, Koichi. Japanese personnel appraisal: individualised race for power and imposed involvement. Trabalho apresentado no seminário Japarnese Maruagement Styles: an intrmational comparative perspective. School of Business, University of Wales College of Cardiff, 1992.

OLIVER, Nick. Human factors in the implementation of Just-in-Time Production. Intnational Joumal of Operations and Production Management, v.10, n.4, 1990.

OLIVER, Nick \& WILKINSON, Barty. The japanisation of British industry. Oxford, Blackwell, 1988.

PIORE, Michael \& SABEL, Charles. The second industrial divide. New York, Basic Books, 1984.

POSTHUME, Anne. Changing production practices and competitive strategies in the Brazilian auto componentes industry. (Tese de doutoramento não publicada), University of Sussex, 1991.

RODRIGUES, Maria Beatriz. Just-in-Time: nopa forma de organizapto de traballbo (Dissertaçăo de mestrado não publicada), Programa de Pós-Graduaçăo em Administraçăo, Universidade Federal do Rio Grande do Sul, 1991.

ROESCH, Sylvia \& ANTUNES, Elaine. O Just-in-Time e a emergência de um novo cargo: o operador multifuncional. Trabalho apresentado no $14^{\circ}$ Encontro Anual da ANPAD, Florianópolis, set. 1990.

ROESE, Mauro. Novas formas de organizafato da producto e relafoes de trabalbo na induistria (Dissertaçăo de mestrado não publicada), Programa de Pós-Graduaçāo em Sociologia, Universidade Federal do Rio Grande do Sul, 1992.

SCHMITZ, Hubert, \& CARVALHO, Ruy de Quadros. Automation and labour in the Brazilians car industry. Joumal of Development Studies, v.26, n.1, 1989.

SCHONBERGER, Richard. Japasnese manufucturing techiniques. New York, Free Press, 1982.

SHAIKEN, Harley. Mexico in the global economy: high technology and work organization in export industries. San Diego, University of California, Centre for U.S. Mexican Studies. Monograph Saries 33, 1990. 
WOMACK, James; JONES, Daniel; ROOS, Daniel The machine that changed the world. New York, Rawson MacMillan, 1990.

WOOD, Adrian. A new-old theoretical view of north-south trade, employment and wages. Brighton, IDS Discuscion Papar 292, 1991.

WOOD, Stephen. Toyotisme et/ou japanisation? In: H. Hirata (ed.), Avtous due "modtlen japonais. Paris, Harmattan, 1992 (próximo).

John Humphrey é sociólogo e presidente da Comissáo de Ensino do Instituto de Estudos sobre Desenvolvimento da Universidade de Sussex, Brighton, Inglaterra. É autor de Fazendo o "milagre", (Vozes, 1982) e Gender and work in the Third World (London, Travistock, 1987).

O autor agradece ao Instituto de Pesquisas Econômicas Aplicadas (Ipea) e à $U K$ Overseas Development Administration pelo suporte das pesquisas realizadas no Brasil, bem como a Afonso Fleury - co-diretor do grupo de pesquisa -, Naira Franzoi, José Antunes, Maria Tereza Leme Fleury, Roberto Marx, Roberto Ruas e Maria Beatriz Rodrigues. As interpretaçóes apresentadas são de responsabilidade do autor.

Traduçáo de Maria Cristina Meyer. Revisáo de Ruy de Quadros Carvalho. O original em inglês - The management of labour and the move towards leaner production systems in the Third World: The case of Brazil - encontra-se à disposiçáo do leitor no IEA para eventual consulta. 